\title{
MULTI-SENSOR RADIOMETRIC STUDY TO DETECT PATHOLOGIES IN HISTORICAL BUILDINGS
}

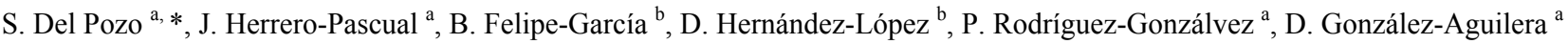 \\ a Dept. of Cartographic and Land Engineering, High School of Ávila, University of Salamanca, Ávila, 05003, Spain - (s.p.aguilera, \\ sabap, pablorgsf, daguilera)@usal.es \\ ${ }^{\mathrm{b}}$ Regional Development Institute-IDR, University of Castilla-La Mancha, Albacete, 02071, Spain - bfelipe@jccm.es, \\ david.hernandez@uclm.es
}

Commission V, WG V/4

KEY WORDS: Architecture, Cultural Heritage, Camera, Multispectral, Laser Scanning, Remote Sensing, Close Range, Classification

\begin{abstract}
:
This paper presents a comparative study with different remote sensing technologies to recognize pathologies in façades of historical buildings. Building materials deteriorate over the years due to different extrinsic and intrinsic agents, so assessing these diseases in a non-invasive way is crucial to help preserve them. Most of these buildings are extremely valuable and some of them have been declared monuments of cultural interest. In this way through close range remote sensing techniques, it is possible to study material pathologies in a rigorous way and in a short duration field campaign.
\end{abstract}

For the investigation two different acquisition systems were applied, active and passive methods. The terrestrial laser scanner FARO Focus 3D was used as active sensor, working at the wavelength of $905 \mathrm{~nm}$. For the case of passive sensors, a Nikon D-5000 and a 6bands Mini-MCA multispectral camera $(530-801 \mathrm{~nm})$ were applied covering visible and near infrared spectral range. This analysis allows assessing the sensor, or sensors combination, suitability for pathologies detection, addressing the limitations according to the spatial and spectral resolution. Moreover, the pathology detection by unsupervised classification methods is addressed in order to evaluate the automation capability of this process.

\section{INTRODUCTION}

Historical buildings and monuments are extremely valuable constructions for the area where they are placed. The degradation of their construction materials is caused mainly by environmental factors such as pollution and meteorological conditions. Water increases the ability of air contaminants to degrade stone by combining with them to produce a hard and blackened layer on the surface of the rock (Marszałek, 2004). In addition, results of previous uncontrolled restoration techniques applied in some cases influence the degradation (Price, 2011). For that reason the use of non-contact and non-destructive technologies to study stone damages is important for the preservation of buildings and for the choice of the best technique for restoration (Fort et al., 2002; Weritz et al., 2009).

Terrestrial laser scanner and digital cameras are two different technologies that are suitable for these studies. They are nondestructive and non-invasive sensors that allow researchers to acquire huge geometric and radiometric information across the building with high accuracy and in a short duration acquisition. The geometrical information provided by laser scanner technology has been successfully applied in a large number of fields such as archaeology (Lamberts et al., 2007), civil engineering (González-Aguilera et al., 2008), geology (Buckley et al., 2008) and geomorphological analysis (Armesto et al., 2009). On the other hand, radiometric information, provided by the intensity measurements in the case of laser technology and by the digital levels in the case of digital cameras, is used less frequently. Even so, it has demonstrated its high potential for classification tasks and recognition of different materials. Nowadays, in the literature, one can find works related to this issue: from methodologies of radiometric calibration
(Kaasalainen et al., 2008), to corrections of intensity values (Franceschi et al., 2009; Höfle and Pfeifer, 2007) and to applications of the intensity data (Lichti, 2005). Spectral classification methods are based on the fact that each specific material has wavelength dependent reflection characteristics. There are many classification methods, which vary in complexity. These methods include hard and soft classifiers, parametric and non-parametric methods and supervised and unsupervised techniques (Mather and Tso, 2003). There are several works related to the application of these techniques to the identification of damage on building surfaces (Lerma, 2001; Lerma, 2005; Ruiz et al., 2002).

The main goal of this study was to compare three different sensors to detect damages in facades of historical buildings. Additional goals were to detect different building materials and also increase the degree of automation in the pathology detection of façades. To succeed these objectives, the paper is divided into the following sections: Section 2 gives the details and specifications of the equipment employed and thoroughly describes the methods employed in the workflow methodology. Section 3 shows the classification results for both unsupervised and supervised algorithms, closing with Section 4 which summarizes the conclusions drawn from the study.

\section{MATERIAL AND METHODS}

Sensors and their role in the workflow developed are outlined in Figure 1. 


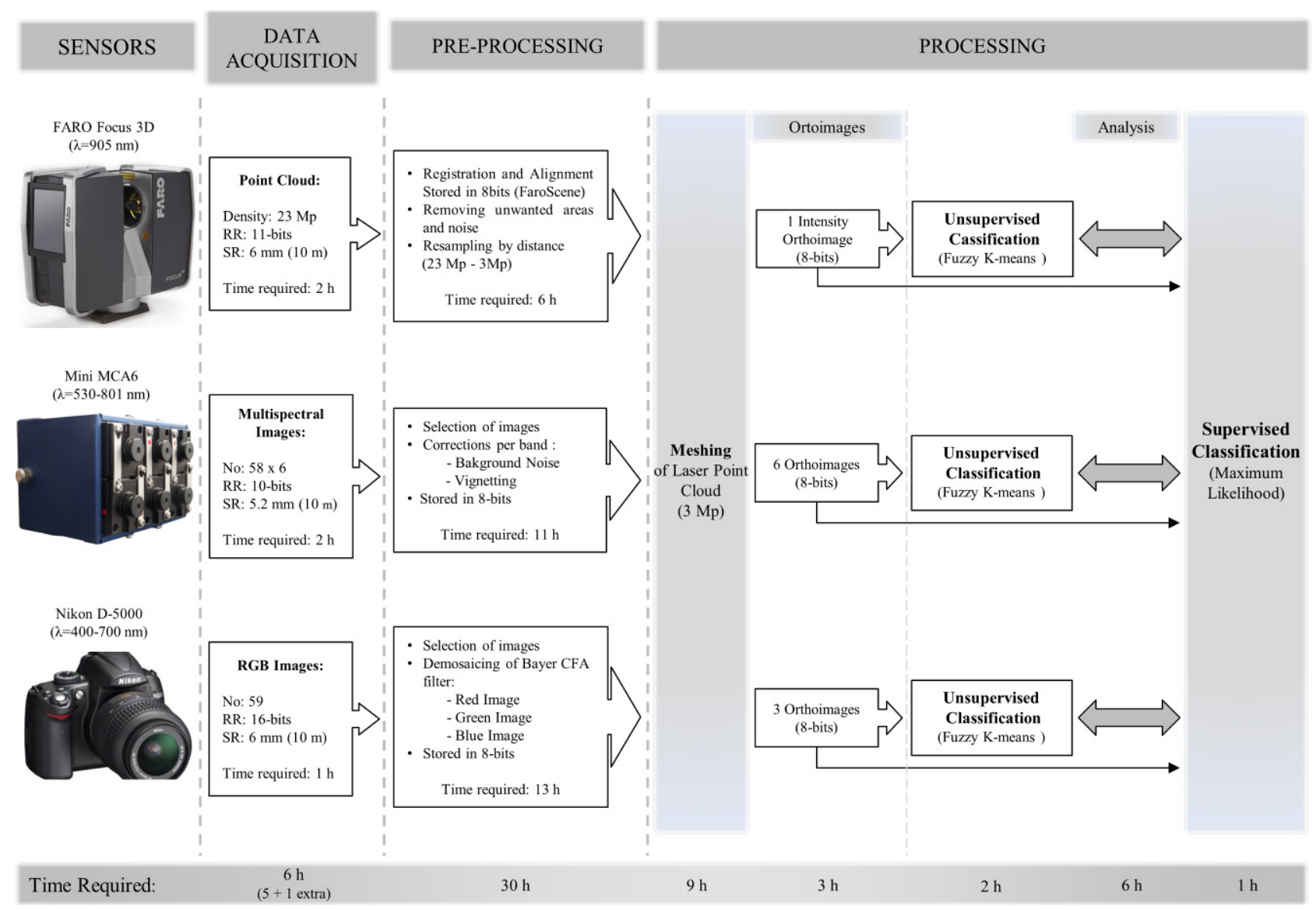

Figure 1. The workflow of the methodology presented. $\mathrm{RR}=$ Radiometric resolution, $\mathrm{SR}=$ Spatial resolution, $\mathrm{Mp}=$ Million points.

\subsection{Equipment}

For the documentation of the façade three different sensors were used with different characteristics and data acquisition principles, one active terrestrial laser scanner and two passive digital cameras (a multispectral camera and a single lens reflexSLR digital camera). Figure 1 shows the different wavelength sensors used in this research.

The FARO Focus 3D laser scanner is based on the principle of continuous wave, with a wavelength of $905 \mathrm{~nm}$. This device measures distances in a range of $0.60-120 \mathrm{~m}$ with a point measurement rate of 976,000 points per second. It has an accuracy of $0.015^{\circ}$ in normal lighting and reflectivity conditions and a beam divergence of $0.19 \mathrm{mrad}$, equivalent to $19 \mathrm{~mm}$ per $100 \mathrm{~m}$ range. The field of view covers $320^{\circ}$ vertically and $360^{\circ}$ horizontally with a $0.009^{\circ}$ of angular resolution and the returning intensity is recorded in 11 bits. This laser scanner includes, in addition, a double compensator in the horizontal and vertical axis that can be used as constraint for the scan alignment.

For the multispectral data acquisition, a lightweight Multiple Camera Array (MCA-6, Tetracam) was employed. This lowcost sensor allows versatility in data acquisition, however requires the radiometric and geometric corrections to ensure the quality of the results (Del Pozo et al., 2014). It includes a total of 6 individual sensors with filters for the visible and near infrared spectrum data acquisition. More concretely, the individual bands of 530, 672, 700, 742, 778 and $801 \mathrm{~nm}$ were used. The longest wavelength was chosen taking into account that the multispectral sensor is not external cooled. In spite of its $1280 \times 1024$ pixels of spatial resolution, the camera has a radiometric resolution of 10 bits. The focal length of $9.6 \mathrm{~mm}$ and the pixel size of $5.2 \mu \mathrm{m}$ yield a façade sample distance (FSD) of $5.4 \mathrm{~mm}$ for a distance of $10 \mathrm{~m}$, which should be taken into account for the pathology detection performance in small elements. The main limitation of this camera is the field of view $\left(38^{\circ} \times 31^{\circ}\right)$, so several captures were needed to keep the FSD.

The Nikon D5000 is a high-resolution digital SLR camera chosen to acquire information relating to the visible range of the spectrum with a resolution of $4288 \times 2848$ pixels. This camera uses RBG CMOS (Complementary Metal-OxideSemiconductor) sensor with a pixel size of $5.5 \mu \mathrm{m}$. The focal length chosen for the study is $18 \mathrm{~mm}$ in order to capture high field of view.

\subsection{Data acquisition}

2.2.1 Range data: For the laser scanner, intensity data at 11-bit resolution was collected at an average distance of $10 \mathrm{~m}$. Scanning positions were selected according to the different technical specifications of the scanner for an spatial resolution of $6 \mathrm{~mm}$ at the working distance. The laser network was adapted and optimized due to the presence of obstacles that hinders a single station data acquisition. 
2.2.2 Image data: Illumination was a crucial parameter for both sensors in the image data acquisition since they were passive sensors and also several shot positions per sensor were required to cover the object of study. For that reason take fewer number of photos and farther was prioritized ensuring the greatest resolution. Images were collected at $10-\mathrm{m}$ distance with a spatial resolution of $5.4 \mathrm{~mm}$ for the worst case (multispectral images).

\subsection{Pre-Processing}

2.3.1 Optimization and alignment of the point clouds: The raw TLS data were filtered and segmented in order to remove those points that were not part of the object of study (adjacent building, artificial elements, trees, etc.). The individual point cloud alignment was done by a solid rigid transformation by the use of external artificial targets (spheres). The spheres were stationed in tripods in the vertical of ground control points (GCP) surveyed by GNSS. The laser local coordinate frame could be transformed to a global coordinate system (UTM30N in ETRS89), allowing the geo-reference of the subsequent classification for a global analysis e interpretation. This proposed workflow allowed a final relative precision of the GCP coordinate of $0.01 \mathrm{~m}$ and an absolute error of $0.03 \mathrm{~m}$ after post-processing. As a result, a unique point cloud in a local coordinate system with $11-\mathrm{mm}$ precision (due to the error propagation of inherent error sources of TLS (Reshetyuk, 2009) and the error associated to the definition of the coordinate frame) was generated.

2.3.2 Multispectral images corrections: Low-cost sensors are more likely to be affected by different noise sources so that the actual value of radiation collected by them is altered (Equation (1)) (Al-amri et al., 2010). The Mini MCA6 was affected by two different sources errors: a background noise and a vignetting effect (Del Pozo et al., 2014). Both errors were studied under laboratory controlled conditions for each wavelength band.

The background noise is a systematic error caused by the sensor electronics of the camera. It was analysed in a completely dark room in the absence of light determining the noise per band and exposure time. For this study, the maximum background error was for the $801-\mathrm{nm}$ band and involved a $1.07 \%$ increment of the actual digital level value. Regarding the vignetting effect, the radially attenuation of the brightness was studied taking images of a white pattern with uniform lighting conditions. Digital levels of each multispectral image were corrected for these two effects through a script developed in Matlab to improve the data quality before the orthoimages generation.

$$
D L_{\text {raw }}=D L_{\text {radiance }}+\left(D L_{b n}+D L_{v}\right)
$$

where $\quad D L_{\text {raw }}=$ digital levels of the raw images

$D L_{\text {radiance }}=$ digital levels from the radiance component

$D L_{b n}=$ digital levels from background noise

$D L_{b n}=$ digital levels from vignetting component
2.3.3 Demosaicing of RGB images: The Nikon D5000 uses a Bayer filter over the CCD (Figure 2). It is a colour filter array (CFA) for arranging the red, green and blue colour filters on a rectangular grid of the sensor ( $\mathrm{Lu}$ and Tan, 2003). Two filtered green, one blue and one red were obtained from each square of four pixels. There is double number of pixels for the green because the human eye is more sensitive to this colour. Each image is a mosaicked image. The process consists of estimate the three colours with the only one spectral measurement stored per pixel according to the neighbouring colours ( $\mathrm{Li}$ et al., 2008). We make use of the open-source dcraw (Coffin, 2011) computer application to convert these images. As result, the demosaiced images enclose the half spatial resolution of the original ones.

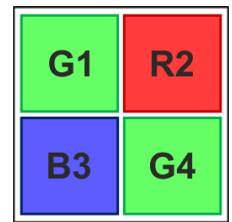

Figure 2. Bayer-pattern block CFA.

\subsection{Processing}

In this section data from the different sensors were joined to achieve the orthoimages of each wavelength and the subsequent classifications maps. The pre-selected images from both cameras and the optimized laser scanner point cloud are the input data of the following procedures.

2.4.1 Meshing: Once the final point cloud was generated a triangulation was applied to create the digital surface model (DSM). This step was required in order to generate continue 2D products (in the form of orthoimages) and carry out the pathology detection by the classification process. For the DSM generation the incremental triangulation Delaunay algorithm was applied (Bourke, 1989). The output was refined to avoid artifact, meshing gaps, and other errors (Attene, 2010).

2.4.2 Orthoimages generation: Orthoimages are highly demanded products that offer many benefits: metric accuracy and radiometric information useful to analyse quantitatively and qualitatively different kind of information.

For the orthoimage generation, there is necessary to known the external orientation of the images with respect to the coordinate system of the laser point model. For that purpose an average of 20 corresponding points between the point cloud and images were establish. The image projection is characterised by a rigid transformation (rotation and translation) together with the internal camera parameters.

Orthoimages were generated based on the anchor point method (Kraus, 1993). This method consists of applying an affine transformation to each one of the planes formed by the optimised triangular mesh, which was obtained from the point cloud determined by the laser. Through the collinearity condition (Albertz and Kreiling, 1989), the pixel coordinates of the vertices of the mesh are calculated, and the mathematical model of the affine transformation directly relates the pixel coordinates of the registered image and of the orthoimage. 
2.4.3 Orthoimages classifications: In order to categorize the orthoimages in different informational classes a firstly unsupervised and a posterior supervised classification were performed. The unsupervised classification was based on the Fuzzy K-means clustering algorithm where each observation can concurrently belong to multiple clusters (Bezdek, 1981). For a set of $n$ multidimensional pixels, the automatic management in $k$ classes iteratively minimizes the Equation (2) (Kannan et al., 2009):

$$
J_{m}=\sum_{i=1}^{n} \sum_{l=1}^{k} u^{m}{ }_{i, l}\left\|x_{i}-c_{j}\right\|^{2} ; 1 \leq m<\infty
$$

where $\quad m=$ any real number greater than 1

$x_{i}=$ the $i$-th of d-dimensional measured data

$u_{\mathrm{i}, 1}=$ degree of membership of $x_{i}$ in the cluster $l$

$c_{l}=d$-dimensional centre of the cluster

$\|* *\|=$ any norm expressing the similarity between

any measured data and the centre

Fuzzy partitioning is carried out through an iterative optimization of the objective function shown above, with the update of membership and the cluster centres by Equation (3).

$$
u_{i, l}=\frac{1}{\sum_{k=1}^{c}\left[\frac{\left\|x_{i}-c_{l}\right\|}{\left\|x_{i}-c k\right\|}\right]^{\frac{2}{m-1}}} ; c_{l}=\frac{\sum_{i=1}^{N} u^{m}{ }_{i l} x_{i}}{\sum_{i=1}^{N} u^{m}{ }_{i l}}
$$

This iteration will stop when $\max _{i l}\left\{\left|u_{i l}{ }^{(k+1)}-u_{i l}{ }^{(k)}\right|\right\}<\varepsilon$

where $\quad \varepsilon=$ termination criterion between 0 and 1

$$
k=\text { the iteration steps }
$$

After this classification, a fist approach of the spectral classes and different construction materials was obtained. With a subsequently supervised classification and applying the expert knowledge of some classes, the final results improve.
Furthermore, this classification will serve as reference to discuss which sensor is the ideal for detecting materials and pathologies in façades.

In this case, a maximum likelihood (ML) classification algorithm (Richards and Richards, 1999) was applied. The ML classifier quantitatively evaluates both the variance and covariance of the category spectral response patterns when classifying an unknown pixel. The resulting bell-shaped surfaces are called probability functions (Equation (4)), and there is one such function for each spectral category (Lillesand et al., 2004).

$$
\operatorname{Pr}(k / g)=-\ln \left|\sum k\right|-\left(g-\mu_{k}\right)^{T} \sum k^{-1}\left(g-\mu_{k}\right)
$$

where

$$
\begin{aligned}
& \sum k=\text { covariance matrix } \\
& w_{k}=\text { mean vector }
\end{aligned}
$$

\section{EXPERIMENTAL RESULTS}

The study area was the Shrine of San Segundo declared World Cultural Heritage in 1923 (García, 2006) (Figure 3). This Romanesque shrine is located in the west of the city of Ávila (Spain) and was built in the 12th century with unaltered grey granite plinths and walls with the alternation of granite blocks with different alteration degrees. The unaltered granite is mainly present in the blocks of low areas because of its high compressive strength and resistance to water absorption.
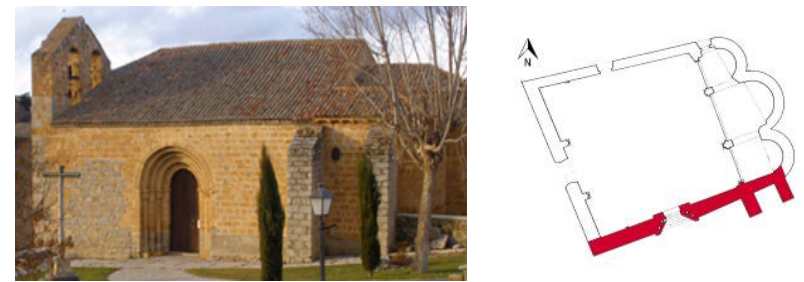

Figure 3. South façade of the Church of San Segundo in Ávila (Spain).

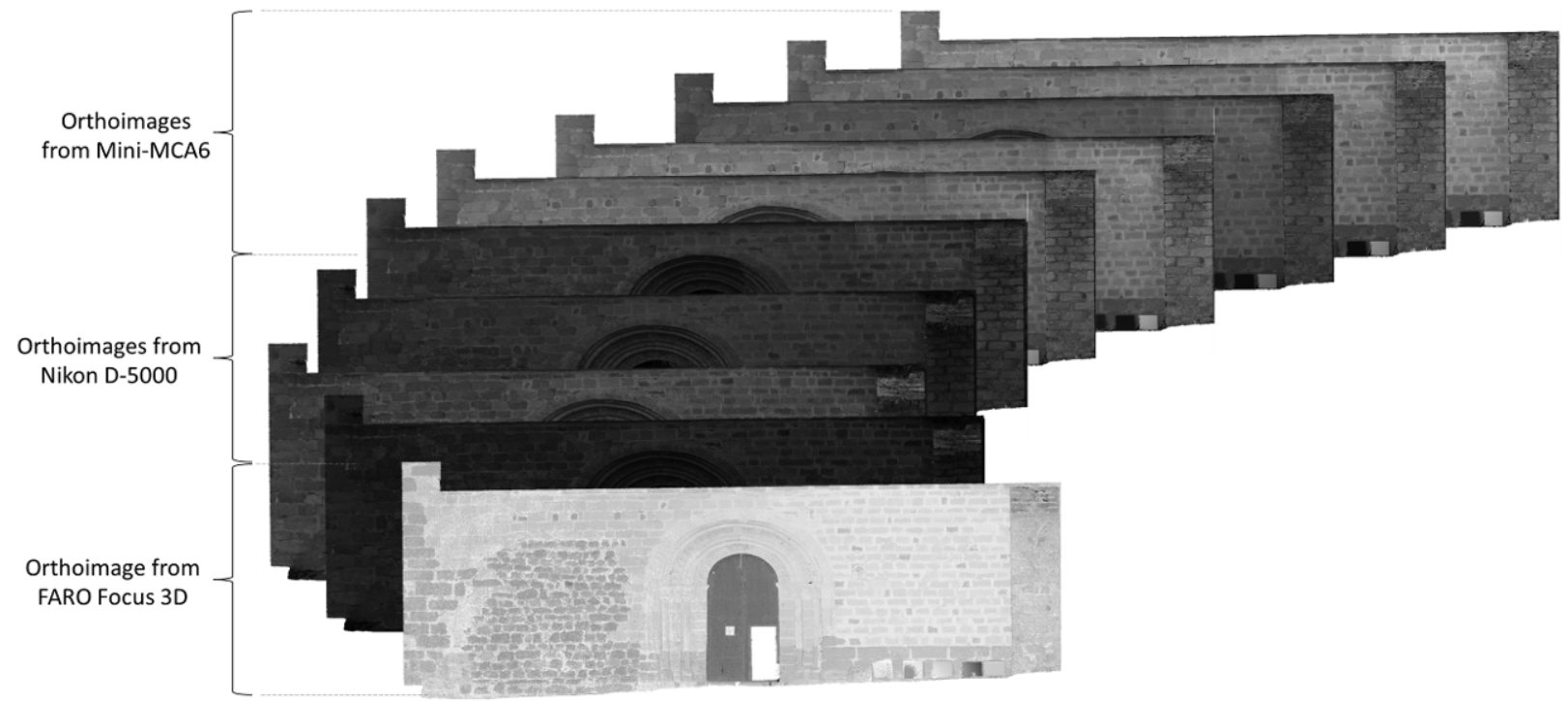

Figure 4. Orthoimages of the southern façade from the 3 analysed sensors. 
The field work was carried out on 27 July 2012 around the southern façade of the church (Figure 3 ), the most interesting façade from a historical point of view because it preserves the Romanesque main front. The five archivolts and capitals are decorated with plant and animal motifs. A total of 3 stations for the case of laser scanner were performed to cover the façade at a distance of $10 \mathrm{~m}$. The resolution of the data capture of the FARO Focus 3D was $6 \mathrm{~mm}$. Moreover, the façade was photographed at the same distance with both passive sensors, Nikon D5000 and Mini MCA6-Tetracam. A total of 3 RGB images and 9 multispectral images were used for the orthoimages generation. The total volume of information generated amounted to $10.7 \mathrm{~GB}$, where the great part was due to the meshes and orthoimages generation projects. Figure 4 shows the set of the 10 final orthoimages.

In order to compare the discrimination capability of the three sensors to distinguish rock and pathologies a first unsupervised classification for the orthoimages of each sensor was performed (Figures 5, 6 and 7). A final supervised classification with the complete set of 10 orthoimages was carried out. This last classification serves as a reference against which compare each individual unsupervised classification. The steps followed by the workflow are shown in Figure 1.

\subsection{Unsupervised classifications}

Ten predefined clusters were used in each case for the unsupervised classification algorithm. In all of them, the resulting map showed the existence of affected areas. Postanalysis reduced the number of clusters. The number of clusters decreased from 10 initial clusters to 6 thematic classes with real meaning: 1) unaltered granite, 2) altered granite, 3) wood (door of the church), 4) areas with moisture evidences (caused by capillarity or filtration water), 5) mortar between blocks and 6) biological colonization areas.

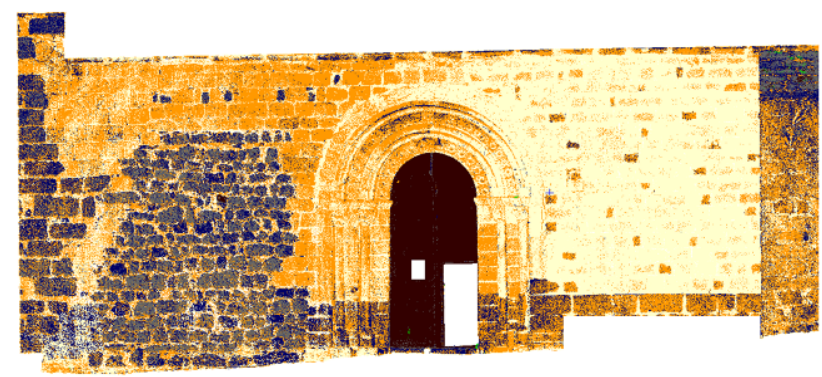

Figure 5. FARO Focus 3D map for the 6-classes unsupervised classification.

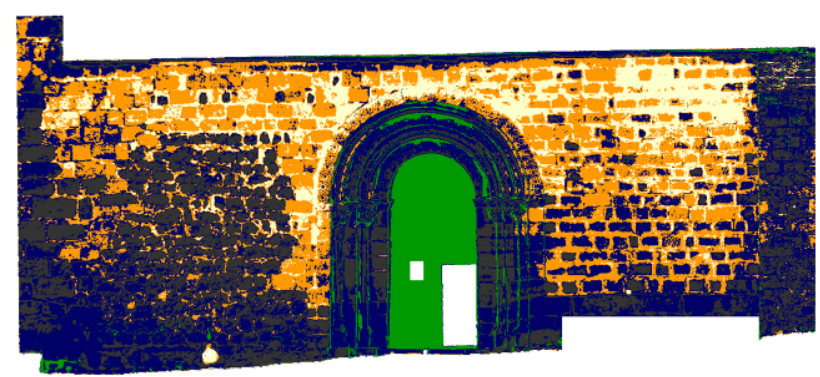

Figure 6. Mini MCA6 map for the 6-classes unsupervised classification.

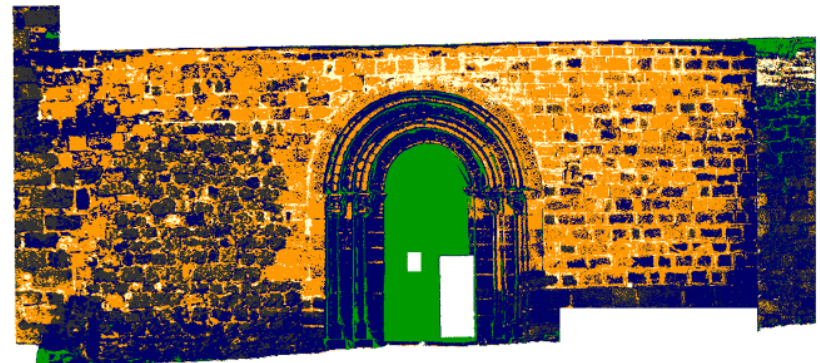

Figure 7. Nikon D5000 map for the 6-classes unsupervised classification.

It is noteworthy that data are not as satisfactory as could be due to large variability in lighting conditions during the data acquisition. As mentioned at the beginning of Section 3 , the fieldwork took place on July 27, with a 6-hours total acquisition time.

Comparing the results with a visual inspection, results corresponds quite well to reality for both types of existing granites (unaltered and altered) by two well differentiated clusters in all classification maps (Figure 5,6 and 7). Note that only 6 clusters of the final 6 pre-set informational classes were distinguished for the case of laser scanner (Figure 5). Regarding pathologies detection, it was not possible to draw conclusions with these first unsupervised classifications. However, this process served to perform a better defined supervised classification.

Table 1 summarizes the values of the overall accuracy for the Fuzzy K-means unsupervised classification for each data set evaluated.

\begin{tabular}{lc}
\hline \multicolumn{2}{c}{ Overall accuracy (\%) } \\
\hline \multicolumn{1}{c}{ Sensor } & Fuzzy K-means algorithm \\
\hline FARO Focus 3D $(905 \mathrm{~nm})$ & 78.96 \\
Mini MCA6 (530-801 nm) & 86.20 \\
Nikon D5000 (Visible) & 75.92 \\
\hline
\end{tabular}

Table 1. Unsupervised classification accuracies achieved for each data set.

The best classification accuracy was $86.20 \%$, achieved for the Mini MCA6 unsupervised classification (Table 1). This indicates that the best correlation between the number of pixels correctly classified and the total number of pixels occurred for this sensor.

\subsection{Supervised classification}

With the full set of the 10 orthoimages a supervised classification of the façade was performed (Figure 8) taking into account the two existing variants of granite and their pathologies derived primarily from moisture and biological colonizations.

In order to compare the reference classification (based on training areas) with each sensor data unsupervised classification Table 2 was performed. The table shows the sum of pixels belonging to each class for each of the classifications performed. The count is expressed as a percentage of the total number of classified pixels. 


\begin{tabular}{lcccc}
\hline $\begin{array}{c}\text { Count of } \\
\text { pixels (\%) }\end{array}$ & $\begin{array}{c}\text { Reference } \\
\text { map }\end{array}$ & $\begin{array}{c}\text { Laser } \\
\text { map }\end{array}$ & $\begin{array}{c}\text { Multispectral } \\
\text { map }\end{array}$ & $\begin{array}{c}\text { Visible } \\
\text { map }\end{array}$ \\
\hline - Unaltered \\
$\begin{array}{l}\text { granite } \\
\text { - Altered }\end{array}$ & 29.29 & 7.77 & 22.17 & 31.98 \\
granite & 14.69 & 34.02 & 25.04 & 18.97 \\
- Wood & 30.65 & 5.72 & 0.00 & 0.00 \\
- Moisture & 21.81 & 12.67 & 34.23 & 35.04 \\
- Mortar & 1.71 & 39.80 & 10.85 & 5.98 \\
- Biological & 1.84 & 0.03 & 7.71 & 8.04 \\
\hline
\end{tabular}

Table 2. Pixels computation belonging for each thematic class.

In a quantitative analysis, intensity data from laser scanner is the furthest from the reference. Results show a high number of pixels classified as mortar in the case of laser map (38.09\% higher with respect to the reference map) and few pixels classified as unaltered granite offset by the altered granite count. For the multispectral and visible passive sensors results are quite similar. For both cases it was not possible to discretize wood from biological colonization so these two classes were exempted from being part of the multi-sensor analysis. Note that in the case of the multispectral camera, moisture classification was closer to reality. Since best results for moisture detection were achieved by the multispectral camera and it is the most comprehensive sensor with results closer to the reference it is concluded that the best of the three sensors to detect pathologies and construction materials differences is the Mini MCA6, which also had the best classification accuracy.

To evaluate the separability between classes the transformed divergence was used as a quantitative estimator (Davis et al., 1978) being the most widely used estimator for this purpose (Tolpekin and Stein, 2009). Table 3 shows the separability between the final 7 classes (taking into account the background or null cluster).

A high separability was achieved for all 7 classes, highlighting the good separability between the two granite types. The worst case was for moisture and unaltered granite. This fact is explained because most of the moisture was part of the unaltered granite. This granite type was constructively situated in lower areas to support the loads of the building (also in buttress), coinciding with the most likely areas to be affected by filtration and capillarity of water. This radiometric misunderstanding did not occur in the case of altered granite since being part of the centre of the façade hardly had moisture.

\begin{tabular}{lcccccc}
\hline & $\begin{array}{c}\text { Unaltered } \\
\text { granite }\end{array}$ & $\begin{array}{c}\text { Altered } \\
\text { granite }\end{array}$ & Wood & Moisture & Mortar & $\begin{array}{c}\text { Biological } \\
\text { colonization }\end{array}$ \\
\hline Altered granite & 1.99 & - & - & - & - & - \\
Wood & 2.00 & 2.00 & - & - & - & - \\
Moisture & 1.51 & 1.99 & 2.00 & - & - & - \\
Mortar & 1.99 & 1.92 & 2.00 & 1.99 & - & - \\
Biological colonization & 1.99 & 2.00 & 2.00 & 1.97 & 1.99 & - \\
Background & 2.00 & 2.00 & 2.00 & 2.00 & 2.00 & 2.00 \\
\hline
\end{tabular}

Table 3. Transformed divergence for the supervised classification.

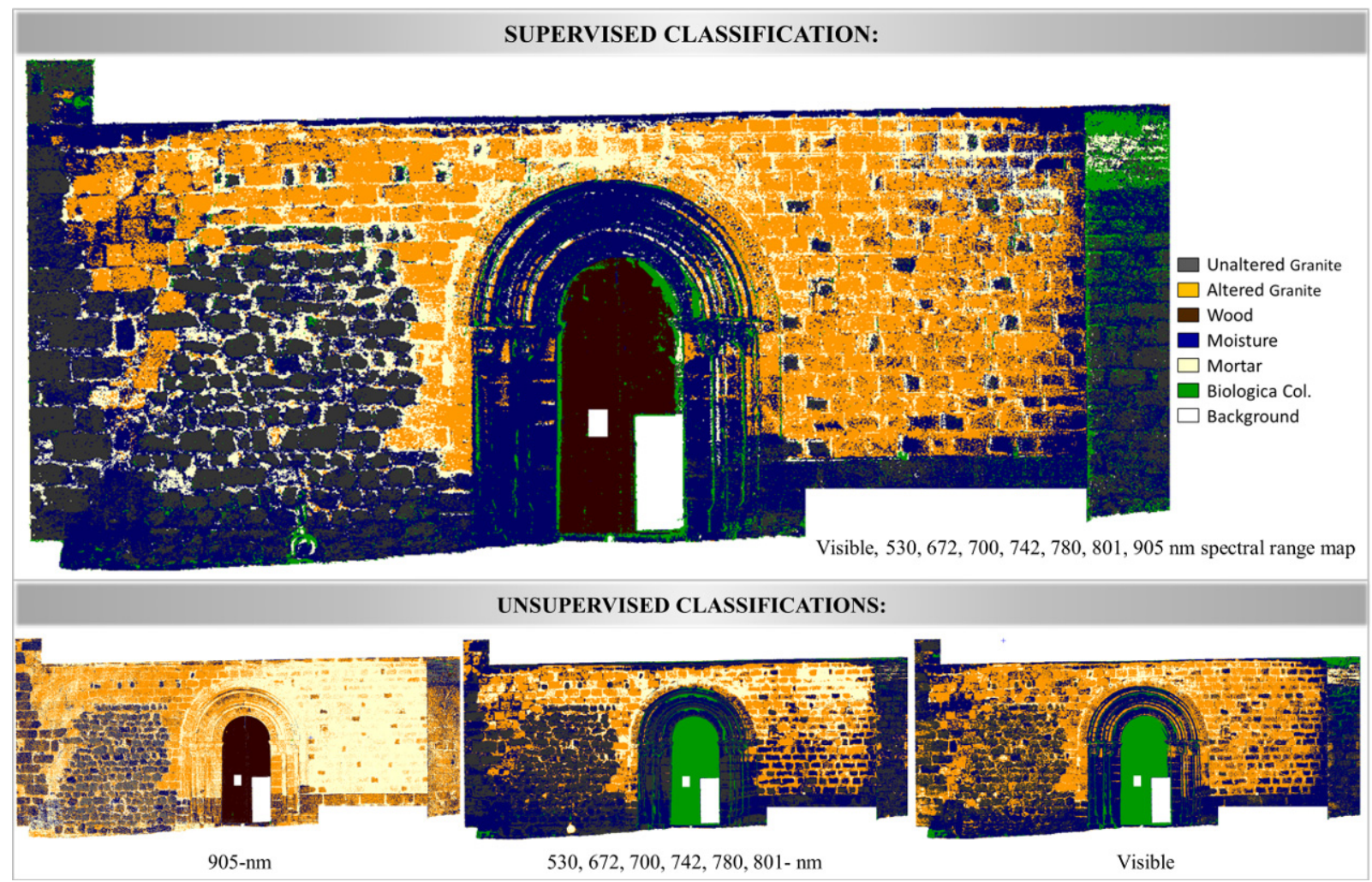

Figure 8. Multisensory map for the 6-classes unsupervised classification. 


\section{CONCLUSIONS}

The work presented in this paper shows a comparison of the classification results of different sensors in the detection of pathologies in materials of historical buildings façades. By combining the use of two different data acquisition techniques (active and passive), three sensors were examined: a 3D laser scanner, a multispectral camera and a digital SLR camera. The results show the different radiometric responses of the ashlars with different damages (mainly moisture and biological colonization) levels. The classification algorithms used for the classification processes were the Fuzzy K-means and the maximum likelihood (ML) classification algorithm.

A complete description of the workflow followed: data acquisition, pre-processing, orthoimages generation, and the application of two classification algorithms to assess the final results was outlined. Our results show that the most comprehensive sensor for which the best results were obtained is the MCA6. This is possibly due to the advantage of having the highest spectral resolution of the three analysed sensors. However, for the limited registration to a single wavelength, the results from the FARO laser scanner were quite good. Furthermore, geometric models of the study object can be derived thanks its data capture. With these models, physical pathologies (such as fissures, desquamations, etc.) could be analysed and both these and chemical pathologies could be quantified. Therefore, by consider all that issues, it is concluded that the best solution for pathology detection and quantification is a sensor combination where laser scanning as a primary choice. By adding the intensity information to visible or multispectral information results of classification improves in a quantitative and a qualitative way.

As future perspective, additionally to the proposed workflow, the possibility of extend the pathological analysis by the georeferenced data, will allow analysing global pattern in areas with high density of cultural heritage elements. Therefore, according to the inherent characteristics of each sensor a specific radiometric calibration of each one will allow working in reflectance values instead of digital levels. The final results will be improved due to variable light conditions will not affect them.

\section{REFERENCES}

\section{References from Books:}

Albertz, J., Kreiling, W., 1989 Photogrammetrisches Taschenbuch. Wichmann.

Bezdek, J. C., 1981. Pattern recognition with fuzzy objective function algorithms. Kluwer Academic Publishers.

Davis, S. M., Landgrebe, D. A., Phillips, T. L., Swain, P. H., Hoffer, R. M., Lindenlaub, J. C., Silva, L. F., 1978. Remote sensing: the quantitative approach. McGraw-Hill, New York.

Fort, R., López de Azcona, M.C., Mingarro, F., 2002. Assessment of protective treatment based on their chromatic evolution: limestone and granite in the Royal Palace of Madrid, Spain. In: Protection and conservation of the cultural heritage of Mediterranean cities. Balkema Publishers, pp. 437-441.
García, F. A. F., 2006. La invención de la iglesia de San Segundo. In: Cofrades y frailes abulenses en los siglos XVI y XVII. Institución Gran Duque de Alba.

Kannan, S. R., Sathya, A., Ramathilagam, S., Pandiyarajan, R., 2009. New robust fuzzy C-Means based gaussian function in classifying brain tissue regions. In: Contemporary computing, Springer Berlin Heidelberg, pp. 158-169.

Kraus, K., 1993. Photogrammetry .Fundamentals and standard processes Vol 1. 4th edition. Dümmler. Bonn, Germany.

Lillesand, T. M., Kiefer, R. W., Chipman, J. W., 2004. Remote sensing and image interpretation. John Wiley \& Sons Ltd.

Marszałek, M., 2004. Deterioration of stone in some monuments exposed to air pollution: a Cracow case study. In: Air polution and cultural heritage. Balkema, London, pp. 151154.

Mather, P., Tso, B., 2003. Classification methods for remotely sensed data. CRC press.

Price, C. A., Doehne, E., 2011. Stone conservation: an overview of current research. Getty Publications.

Richards, J. A., Richards, J. A., 1999. Remote sensing digital image analysis (Vol. 3). Springer, Berlin.

\section{References from Journals:}

Al-amri, S.S., Kalyankar, N.V., Khamitkar, S.D., 2010. A comparative study of removal noise from remote sensing image. International journal of computer science issues, 7(1), pp. 10021148 .

Armesto, J., Ordóñez, C., Alejano, L., Arias, P., 2009. Terrestrial laser scanning used to determine the geometry of a granite boulder for stability analysis purposes. Geomorphology, 106(3-4), pp. 271-277.

Attene, M., 2010. A lightweight approach to repairing digitized polygon meshes. The Visual Computer, 26(11), pp. 1393-1406.

Buckley, S. J., Howell, J. A., Enge, H. D., Kurz, T. H., 2008. Terrestrial laser scanning in geology: data acquisition, processing and accuracy considerations. Journal of the Geological Society, 165(3), pp. 625-638.

Del Pozo, S., Rodríguez-Gonzálvez, P., Hernández-López, D., Felipe-García, B., 2014. Vicarious radiometric calibration of a multispectral camera on board an unmanned aerial system. Remote Sensing, 6(3), pp. 1918-1937.

Franceschi, M., Teza, G., Preto, N., Pesci, A., Galgaro, A., Girardi, S., 2009. Discrimination between marls and limestones using intensity data from terrestrial laser scanner. ISPRS journal of photogrammetry and remote sensing, 64(6), pp. 522-528.

González-Aguilera, D., Gómez-Lahoz, J., Sánchez, J., 2008. A new approach for structural monitoring of large dams with a three-dimensional laser scanner. Sensors, 8(9), pp. 5866-5883.

Höfle, B., Pfeifer, N., 2007. Correction of laser scanning intensity data: Data and model-driven approaches. ISPRS journal of photogrammetry and remote sensing, 62(6), pp. 415433. 
Kaasalainen, S., Kukko, A., Lindroos, T., Litkey, P., Kaartinen, H., Hyyppa, J., Ahokas, E., 2008. Brightness measurements and calibration with airborne and terrestrial laser scanners. IEEE transactions on geoscience and remote sensing, 46(2), pp. 528534.

Lambers, K., Eisenbeiss, H., Sauerbier, M., Kupferschmidt, D., Gaisecker, T., Sotoodeh, S., Hanusch, T., 2007. Combining photogrammetry and laser scanning for the recording and modelling of the late intermediate period site of Pinchango Alto, Palpa, Peru. Journal of archaeological science, 34(10), pp. 1702-1710.

Lerma, J. L., 2001. Multiband versus multispectral supervised classification of architectural images. The photogrammetric record, 17(97), pp. 89-101.

Lerma, J. L., 2005. Automatic plotting of architectural façades with multispectral images. Journal of surveying engineering, 131(3), pp. 73-77.

Lichti, D. D., 2005. Spectral filtering and classification of terrestrial laser scanner point clouds. The photogrammetric record, 20 (111), pp. 218-240.

Lu, W., Tan, Y. P., 2003. Color filter array demosaicking: new method and performance measures. IEEE transactions on image processing, 12(10), pp. 1194-1210.

Tolpekin, V. A., Stein, A., 2009. Quantification of the effects of land-cover-class spectral separability on the accuracy of Markov-random-field-based superresolution mapping. IEEE transactions on geoscience and remote sensing, 47(9), pp. 32833297.

Weritz, F., Kruschwitz, S., Maierhofer, C., Wendrich, A., 2009. Assessment of moisture and salt contents in brick masonry with microwave transmission, spectral-induced polarization, and laser-induced breakdown spectroscopy. International journal of architectural Heritage, 3(2), pp. 126-144.

\section{References from Other Literature:}

Bourke, P., 1989. An algorithm for interpolating irregularlyspaced data with applications in terrain modelling. In: Pan Pacific computer conference, Beijing, China. 6 pages.

Li, X., Gunturk, B., Zhang, L., 2008. Image demosaicing: a systematic survey. In: Proceedings SPIE 6822, Visual communications and image processing, pp. 68221J-68221J.

Reshetyuk, Y., 2009. Self-calibration and direct georeferencing in terrestrial laser scanning. PhD thesis, KTH - Royal Institute of Technology, Stockholm, Sweden.

Ruiz, L. A., Lerma, J. L., Gimeno, J. 2002. Application of computer vision techniques to support in the restoration of historical buildings. In: The international archives of the photogrammetry, remote sensing and spatial information sciences, Graz, Austria, Vol. XXXIV, Part 3A+B, pp. 227-230.

References from Websites (Last accessed on 2015, Jan. 24):

Coffin, D. 2011. Raw digital photo decoding. https://www.cybercom.net/ dcoffin/dcraw/. 